05

\title{
Чувствительность к механическим воздействиям бинарных смесей на основе нанопористого кремния
}

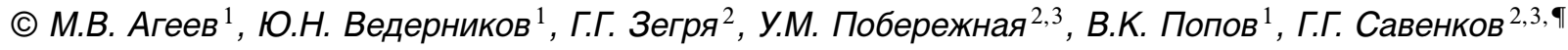 \\ ${ }^{1}$ Научно-производственное предприятие „Краснознаменец“, Санкт-Петербург, Россия \\ ${ }^{2}$ Физико-технический институт им. А.Ф. Иоффее РАН, Санкт-Петербург, Россия \\ ${ }^{3}$ Санкт-Петербургский государственный технологический институт (Технический университет), Санкт-Петербург, Россия \\ "E-mail: sav-georgij@yandex.ru
}

Поступило в Редакцию 9 декабря 2019 г.

В окончательной редакции 12 декабря 2019 г.

Принято к публикации 12 декабря 2019 г.

Представлены результаты экспериментов по определению чувствительности к механическим воздействиям (удару и трению) на копрах К-44-1 и К-44-3 бинарных смесей на основе нанопористого кремния с различными окислителями. Проведено сравнение полученных результатов с данными по чувствительности штатных инициирующих взрывчатых веществ.

Ключевые слова: нанопористый кремний, инициирующее взрывчатое вещество, чувствительность, удар, трение.

DOI: 10.21883/PJTF.2020.05.49110.18144

В большинстве работ, в том числе обзорных [1], отмечается, что энергоемкие композиционные материалы (ЭКМ) на основе нанопористого кремния (в качестве горючего) с добавками различных перхлоратов (в качестве окислителей) могут в перспективе заменить штатные инициирующие взрывчатые вещества (ИВВ). Такая замена прежде всего связана с тем, что в штатные ИВВ входят тяжелые металлы, такие как ртуть, свинец и кадмий, являющиеся экологически грязными веществами, влияющими в том числе на здоровье людей, занятых в производстве средств инициирования, для снаряжения которых предназначены ИВВ. ЭКМ на основе нанопористого кремния показали достаточно хорошие результаты при их инициировании с помощью электрофизических воздействий (высоковольтного разряда, электрического взрыва полупроводников и сильноточного электронного пучка) [2,3].

Общеизвестно, что ИВВ должны быть достаточно чувствительны к простому механическому импульсу, в частности к удару. Чувствительность ИВВ к удару исследуется для оценки как опасности обращения, так и безотказности их действия при служебном применении. Кроме чувствительности ИВВ к удару обычно определяют и их чувствительность к трению, которая характеризует ИВВ с точки зрения выполнения требований техники безопасности при их изготовлении и использовании.

Кроме непосредственного определения чувствительности ИВВ к удару с целью ее прогнозирования желательно также и понимание ее природы, что в принципе является основой как для разработки новых ИВВ, так и для их правильного выбора и применения.

В свете отмеченного выше возникает необходимость 1) определения чувствительности к механическому воз- действию наиболее исследуемых в настоящее время бинарных энергоемких смесей на основе порошкообразного нанопористого кремния, параметры которого приведены, например, в [1]; 2) разработки на основании полученных результатов механизма возбуждения и развития взрывчатых превращений при ударных воздействиях. Именно этому и посвящена настоящая работа.

В первую очередь для исследований были выбраны смеси нанопористого кремния с неорганическими окислителями - перхлоратами (которые являются слабыми взрывчатыми веществами с малым тепловыделением [4]): por- $\mathrm{Si}+\mathrm{Ca}\left(\mathrm{ClO}_{4}\right)_{2}$ (перхлорат кальция), por $-\mathrm{Si}+\mathrm{NaClO}_{4}$ (перхлорат натрия), por- $\mathrm{Si}+\mathrm{Ba}\left(\mathrm{ClO}_{4}\right)_{2}$ (перхлорат бария).

Поскольку любые взрывчатые составы на основе перхлоратов считаются очень чувствительными к механическим воздействиям [5], в качестве четвертого окислителя был выбран нитрат кальция. Выбор данного окислителя объясняется тем, что вследствие сравнительно большей стойкости нитратные составы обладают меньшей чувствительностью к механическим воздействиям. Таким образом, четвертая бинарная смесь por $-\mathrm{Si}+\mathrm{Ca}\left(\mathrm{NO}_{3}\right)_{2}$ (нитрат кальция).

Однако все три указанных выше перхлората, а также нитрат кальция являются сильно гигроскопичными веществами (в меньшей степени перхлорат бария, но он сильно токсичен). Кроме того, при применении перхлоратов в качестве компонентов капсюльных составов они будут оржавлять стенки канала ствола стрелковопушечного оружия. Поэтому в качестве пятого окислителя был выбран $\mathrm{KMnO}_{4}$ - марганцовокислый калий (калиевая соль марганцовой кислоты или перманганат калия). 
Таблица 1. Кислородные эквиваленты окислителей и температура разложения

\begin{tabular}{|c|c|c|c|c|c|c|c|}
\hline \multirow{2}{*}{$\begin{array}{l}\text { Соль } \\
\text { (молекулярная } \\
\text { масса, g/mol) }\end{array}$} & \multicolumn{3}{|c|}{ Полное восстановление } & \multirow{2}{*}{$\begin{array}{c}T_{d e c}, \\
{ }^{\circ} \mathrm{C}\end{array}$} & \multicolumn{3}{|c|}{ Неполное восстановление } \\
\hline & $\begin{array}{c}\mathrm{O}_{2} \\
\%\end{array}$ & $\begin{array}{l}\text { Эквива- } \\
\text { лент }\end{array}$ & $\begin{array}{c}\text { Продукты } \\
\text { восстановления }\end{array}$ & & $\begin{array}{c}\mathrm{O}_{2}, \\
\%\end{array}$ & $\begin{array}{c}\text { Эквива- } \\
\text { лент }\end{array}$ & $\begin{array}{c}\text { Продукты } \\
\text { восстановления }\end{array}$ \\
\hline $\mathrm{Ca}\left(\mathrm{ClO}_{4}\right)_{2}(238.98)$ & 53.6 & 1.87 & $\mathrm{CaCl}_{2}$ & 300 & - & - & - \\
\hline $\mathrm{NaClO}_{4}(122.45)$ & 52.7 & 1.91 & $\mathrm{NaCl}$ & 482 & - & - & - \\
\hline $\mathrm{Ba}\left(\mathrm{ClO}_{4}\right)_{2}(336.23)$ & 38.0 & 2.63 & $\mathrm{BaCl}_{2}$ & 477 & - & - & - \\
\hline $\mathrm{Ca}\left(\mathrm{NO}_{3}\right)_{2}(164.10)$ & 58.5 & 1.71 & $\mathrm{Ca}$ & 500 & 48.8 & 2.05 & $\mathrm{CaO}$ \\
\hline $\mathrm{KMnO}_{4}(158.03)$ & 40.3 & 2.47 & $\mathrm{~K}, \mathrm{Mn}$ & 240 & 25.3 & 3.94 & $\mathrm{~K}_{2} \mathrm{O}$ \\
\hline & & & & & & & $\mathrm{MnO}$ \\
\hline
\end{tabular}

В табл. 1 приведены процентное содержание кислорода в окислителях и их кислородные эквиваленты масса окислителя в граммах, которая требуется для выделения $1 \mathrm{~g}$ кислорода при полном (или неполном) его восстановлении, а также температура разложения данных окислителей.

Отметим, что в работе [6] проводились исследования влияния содержания водорода и удельной поверхности на чувствительность к удару бинарной смеси por- $\mathrm{Si}+\mathrm{Ca}\left(\mathrm{ClO}_{4}\right)_{2}$. Исследования выполнялись по методике оценки чувствительности к удару инициирующих веществ, близкой к способу Веллера-Венцельберга при меньших массах падающего груза [7]. Испытания проводились на устройстве, смонтированном на базе прибора К-III-1. В опытах груз падал с высоты $H$, диапазон значений которой составлял от 100 до $700 \mathrm{~mm}$. Грузы имели массу 50, 100 и 300 g. В качестве параметра, характеризующего чувствительность, использовалось значение энергии инициирования $E_{i}-$ энергии удара, при которой чувствительность к удару составляет $0 \%$. В зависимости от площади удельной поверхности было получено $E_{i}=0.05-68.8 \mathrm{~J}$.

Если в случае определения чувствительности взрывчатых веществ (ВВ) к трению существует ГОСТ P 50835-95, то нормативные методики для определения чувствительности ИВВ к удару в настоящее время отсутствуют. Поэтому чувствительность к удару бинарных смесей определялась на копре конструкции Козлова К-44-1, который применялся для нахождения чувствительности к ударному воздействию ИВВ [8]. Для сравнения были также установлены нижний и верхний пределы чувствительности широко известных ИВВ, таких как гремучая ртуть, азид свинца, и псевдоинициирующего ВB ТНРС (тринитрорезорцинат свинца или стифнат свинца).

Технология изготовления навесок бинарных смесей для испытаний была одинакова для всех четырех окислителей. В ролик копра К-44-1 засыпалась навеска por-Si массой $12 \mathrm{mg}$, окислители растворялись в этаноле и ацетоне $\left(\mathrm{NaClO}_{4}, \mathrm{KMnO}_{4}\right)$ и раствором пропитывалась навеска нанопористого кремния. Операция пропитки повторялась несколько раз после испарения растворителя до тех пор, пока суммарная масса навески окислителя

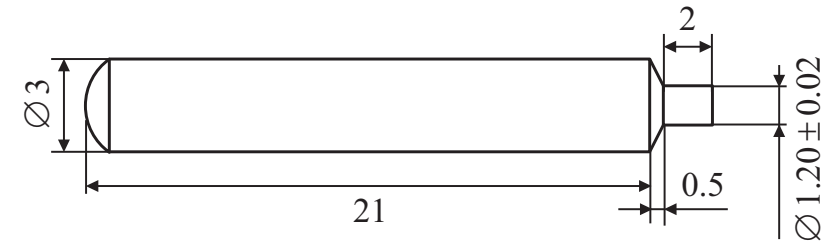

Рис. 1. Боек копра К-44-1.

не достигала $\sim 17 \pm 2 \mathrm{mg}$. После последней пропитки еще не до конца высохшая навеска прессовалась под давлением $100 \mathrm{MPa}$.

После прессования ролик устанавливался в матрицу копра, и через отверстие направляющей втулки вставлялся боек массой $1.13 \mathrm{~g}$ из стали марки У10А. Форма бойка приведена на рис. 1. На боек с различной высоты падал груз массой $0.2 \mathrm{~kg}$. Начальная (она же максимальная) высота падения груза во всех экспериментах составляла $25 \mathrm{~cm}$.

В наших испытаниях при начальной высоте $25 \mathrm{~cm}$, а затем и при высоте $10 \mathrm{~cm}$ произошло 100\% срабатывание всех навесок, кроме навесок ЭКМ por $-\mathrm{Si}+\mathrm{KMnO}_{4}$. Для данной навески уже высота $25 \mathrm{~cm}$ оказалась высотой $100 \%$ отказов. Такой результат для этой смеси, вероятно, был связан с низкой растворимостью $\mathrm{KMnO}_{4}$ в ацетоне $(2.14 \mathrm{~g} / 100 \mathrm{ml})$. В последующих экспериментах бинарная смесь por $-\mathrm{Si}+\mathrm{KMnO}_{4}$ не участвовала.

В испытаниях при высоте падения груза $5 \mathrm{~cm}$ также произошло $100 \%$ срабатывание всех четырех навесок оставшихся бинарных смесей, т.е. $H_{100}=5 \mathrm{~cm}$. Высота, при которой происходило $100 \%$ отказов, в наших экспериментах составила $H_{0}=3 \mathrm{~cm}$. Данные значения высот исследованных бинарных смесей меньше высот $H_{0}=3.5 \mathrm{~cm}, H_{100}=9.5 \mathrm{~cm}$ для такого чувствительного ИВВ, как азид свинца (ГОСТ 1905-69), и высот $H_{0}=4 \mathrm{~cm}, H_{100}=10 \mathrm{~cm}$ для псевдоинициирующего ВВ ТНРС (ГОСТ 1944-80), но выше, чем у гремучей ртути, для которой $H_{100}=4.3 \mathrm{~cm}$, а $H_{0}=2.5 \mathrm{~cm}$.

Сводные данные по чувствительности к удару исследованных бинарных смесей (кроме смеси por $-\mathrm{Si}+\mathrm{KMnO}_{4}$ ) и классических (штатных) ИВВ приведены в табл. 2. Энергия инициирования у всех ис- 
Таблица 2. Чувствительность к удару и трению ИВВ и бинарных смесей

\begin{tabular}{c|l|c|r|r|r}
\hline \multirow{2}{*}{$\begin{array}{c}\text { № } \\
\text { п/п }\end{array}$} & $\begin{array}{c}\text { Бинарные смеси } \\
\text { и штатные ИВВ }\end{array}$ & \multicolumn{2}{|c|}{$\begin{array}{c}\text { Чувствительность } \\
\text { к удару }\end{array}$} \\
\cline { 3 - 6 } & & $H_{0}, \mathrm{~cm}$ & $H_{100}, \mathrm{~cm}$ & \multicolumn{2}{|c}{$\begin{array}{c}\text { Чувствительность } \\
\text { к трению }\end{array}$} \\
\cline { 3 - 6 } & Бинарные смеси & 3.0 & 5.0 & 60.0 & 150.0 \\
2 & Гремучая ртуть & 2.5 & 4.3 & 22.4 & 89.6 \\
3 & Азид свинца & 3.5 & 9.5 & 57.6 & 300.0 \\
4 & ТНРС & 4.0 & 10.0 & 44.8 & 360.0
\end{tabular}

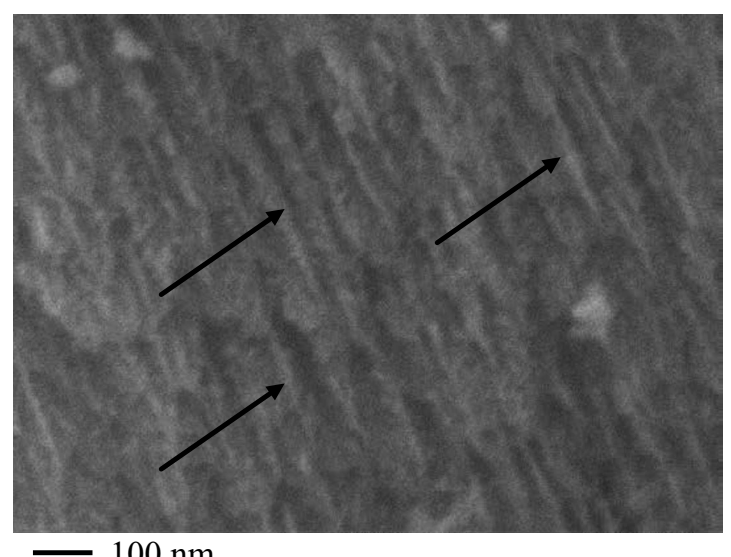

Рис. 2. Снимок поперечного скола нанопористого кремния, полученный с помощью сканирующего электронного микроскопа (стрелками указаны каналы пор).

следованных смесей (за исключением por- $\mathrm{Si}+\mathrm{KMnO}_{4}$ ) оказалась равной $E_{i}=0.06 \mathrm{~J}$, что вполне совпадает с результатами работы [6].

Изучение чувствительности к трению исследованных смесей и штатных ИВВ проводилось на копре К-44-3 в соответствии с ГОСТ Р 50835-95. Полученные результаты также содержатся в табл. 2.

За счет чего же достигается такая высокая чувствительность к удару исследованных бинарных смесей? При этом бинарные смеси обладают неплохими показателями по чувствительности к трению, хотя верхний предел не очень высок и в 2 раза ниже, чем у азида свинца. В [9] сделан вывод, что в системе окислитель+горючее возбуждение взрыва при ударе осуществляется по очаговому механизму и протекание химических реакций в существенной мере зависит от физико-химического взаимодействия окислителя и горючего компонента. При этом для образования горячих очагов необходимо прежде всего возбудить реакцию разложения окислителя, а затем обеспечить условия для химического взаимодействия продуктов его распада с горючим компонентом. Однако в цитируемой работе [9] испытания в условиях распространения детонации на пределе по определению критического напряжения возбуждения взрыва в системе $\mathrm{NH}_{4} \mathrm{ClO}_{4}$ (перхлорат аммония) + ПММА (полиметилметакрилат) проводились в приборе № 2 (ГОСТ 4545-88), в котором на навеску ВВ (или взрывчатой композиции) сбрасывается груз массой 10 или $2 \mathrm{~kg}$. При этом высота сбрасывания груза выбиралась из ряда от 50 до $500 \mathrm{~mm}$.

Поскольку энергия инициирования исследуемых нами образцов минимум на четыре порядка меньше энергии инициирования бинарной смеси $\mathrm{NH}_{4} \mathrm{ClO}_{4}+$ ПММА, возбуждение взрыва по очаговому механизму, описанному [9], в нашем случае отсутствует. По этой же причине не следует ожидать возбуждения взрыва за счет таких механизмов локального разогрева, как адиабатическое сжатие газовых включений или возможность возникновения реакции при пластическом течении поры в окрестности ее схлопывания. Таким образом, можно сделать вывод о том, что возбуждение взрыва происходит вследствие процессов, происходящих в горючем (нанопористом кремнии), которые воздействуют на окислитель. В рассматриваемом случае, на наш взгляд, существуют два вероятных механизма возбуждения взрывчатого превращения бинарных смесей. Первый связан с массовым образованием механических искр (удара и трения), которые воспламеняют бинарную смесь. Толщина межпоровых стенок составляет от единиц до нескольких десятков нанометров (рис. 2), поэтому даже такое слабое воздействие, которое испытывает бинарная смесь, приводит к их массовому разрушению и образованию ударных искр. Искры трения могут образовываться при трении тангенциально взаимодействующих прижатых при ударе частиц и при трении между боковой образующей ударной поверхности бойка и частицами por-Si. На такой сценарий развития процесса указывает и горение нанопористого кремния без наполнителя [10]. Поскольку, как было отмечено выше, межмолекулярные и межатомные связи в окислителе при ударе ослаблены, это, вероятно, облегчает его воспламенение.

Второй возможный механизм возбуждения реакции взрывчатого превращения заключается в следующем. Межпоровые стенки por-Si находятся в сильно напряженном состоянии [1]. В этом случае в частицах por-Si возможно проявление пьезоэлектрических эффектов и, как следствие, образование плазменных (искровых) каналов. 
Нельзя также полностью исключать и механизм трения при разрушении нанопоры, в которой находится окислитель.

Проведенные экспериментальные исследования чувствительности к механическим воздействиям (удару и трению) простейших бинарных смесей на основе нанопористого кремния позволяют сделать следующие выводы.

1. Чувствительность исследованных бинарных смесей к механическим воздействиям находится на уровне чувствительности штатных инициирующих взрывчатых веществ.

2. Чувствительность изученных бинарных смесей к механическим воздействиям не зависит от типа окислителя, а определяется процессами, происходящими в нанопористом кремнии или на границе раздела кремний-окислитель.

3. Вероятной причиной возбуждения взрывчатых превращений при механических воздействиях в исследованных бинарных смесях является образование механических искр (удара и трения) либо искр пьезоэлектрического происхождения, которые воспламеняют бинарную смесь.

\section{Финансирование работы}

Работа выполнена при поддержке Российского фонда фундаментальных исследований (грант № 16-2901085 офи_м).

\section{Конфликт интересов}

Авторы заявляют, что у них нет конфликта интересов.

\section{Список литературы}

[1] Савенков Г.Г., Зегря А.Г., Зегря Г.Г., Румянцев Б.В., Синани А.Б., Михайлов Ю.М. // ЖТФ. 2019. Т. 89. В. 3. C. 397-403.

[2] Зегря Г.Г., Савенков Г.Г., Морозов В.А., Зегря А.Г., Улин Н.В., Улин В.П., Лукин А.А., Брагин В.А., Оськин И.А., Михайлов Ю.М. // ФТП. 2017. Т. 51. В. 4. C. $501-506$.

[3] Савенков Г.Г., Кардо-Сысоев А.Ф., Зегря Г.Г., Оськин И.А., Брагин В.А., Зегря А.Г. // Письма в ЖТФ. 2017. Т. 43. В. 19. C. $57-63$.

[4] Корабельников Д.В., Журавлев Ю.Н. // ФТТ. 2016. Т. 58. B. 6. C. $1129-1134$.

[5] Горст А.Г. Пороха и взрывчатые вещества. М.: Машиностроение, $1972.205 \mathrm{c.}$

[6] Михайлов Ю.М., Гаранин В.А., Ганин Ю.В., Гончаров Т.К., Ганина Л.В., Зегря Г.Г. // Изв. АН. Сер. хим. 2016. № 10. C. $2400-2404$.

[7] Холево Н.А. Чувствительность взрывчатых веществ к удару. М.: Машиностроение, 1974. 136 с.

[8] Багал Л.И. Химия и технология инициирующих взрывчатых веществ. М.: Машиностроение, 1975. 456 с.
[9] Карпухин И.А., Боболев В.К., Балинеи, Ю.М., Степашкин Б.П., Теселкин В.А. // Физика горения и взрыва. 1979. № 2. C. 140-146.

[10] Лазарук С.К., Долбик А.В., Жагиро П.В., Лабунов В.А., Борисенко В.Е. // ФТП. 2005. Т. 39. В. 8. С. 917-919. 